\title{
Antioxidant and polyphenol content of different Vitis vinifera seed cultivars and two facilities of production of a functional bakery product
}

\author{
Viktória Kapcsándi ${ }^{1} \cdot$ Erika Hanczné Lakatos $^{1} \cdot$ Beatrix Sik $^{1} \cdot$ László Ádám Linka $^{1} \cdot$ Rita Székelyhidi $^{1}$ D
}

Received: 20 April 2021 / Accepted: 23 June 2021 / Published online: 27 June 2021

(c) The Author(s) 2021

\begin{abstract}
This study aimed to examine the differences between the antioxidant capacity, and the total polyphenol content of the seed of eight different grape varieties. We also attempt to create a functional loaf enriched with grape seed meal. To achieve this goal, 3, 6, and $9 \%$ of the grape seed meal were added to the loaves made of bread flour and gluten-free flour mixture, and then the changes in their antioxidant and polyphenol content were examined. Based on the results, there were significant differences between the polyphenol and antioxidant content of grape seed varieties. The antioxidant content of the grape seeds varied between $228.50 \mathrm{mg} \mathrm{AAE} / \mathrm{g}(94.80 \mathrm{mg} \mathrm{TE} / \mathrm{g})$ and $438.33 \mathrm{mg} \mathrm{AAE} / \mathrm{g}(181.86 \mathrm{mg} \mathrm{TE} / \mathrm{g})$ in case of fatty samples, and between $176.29 \mathrm{mg} \mathrm{AAE} / \mathrm{g}(41.24 \mathrm{mg} \mathrm{TE} / \mathrm{g})$ and $424.91 \mathrm{mg} \mathrm{AAE} / \mathrm{g}(99.40 \mathrm{mg} \mathrm{TE} / \mathrm{g})$ in case of defatted samples. The total polyphenol content of the fatty samples changed between 91.16 and $221.81 \mathrm{mg} \mathrm{GAE} / \mathrm{g}$; in case of defatted samples, it ranged from 46.01 to $207.68 \mathrm{mg} \mathrm{GAE} / \mathrm{g}$. Rhine Riesling contained the greatest amount of these compounds. The functionality of loafs was confirmed by spectrophotometric analysis. Total polyphenol content ranged from 0.91 to $3.16 \mathrm{mg} \mathrm{GAE} / \mathrm{g}$ in case of wheat loafs, and from 1.39 to $5.92 \mathrm{mg} \mathrm{GAE} / \mathrm{g}$ in case of gluten-free loafs, while the total antioxidant content changed between 0.70 and $6.44 \mathrm{mg} \mathrm{AAE} / \mathrm{g}$ in case of wheat loafs, and ranged from 2.55 to 9.75 in case of gluten-free loafs.
\end{abstract}

Rita Székelyhidi

szekelyhidi.rita@sze.hu

Viktória Kapcsándi

kapcsandi.viktoria@sze.hu

Erika Hanczné Lakatos

lakatos.erika@sze.hu

Beatrix Sik

sik.beatrix@sze.hu

László Ádám Linka

linkalaszlo565@gmail.com

1 Department of Food Science, Faculty of Agricultural and Food Sciences, Széchenyi István University, Lucsony street 15-17, Mosonmagyaróvár 9200, Hungary 


\section{Graphic abstract}

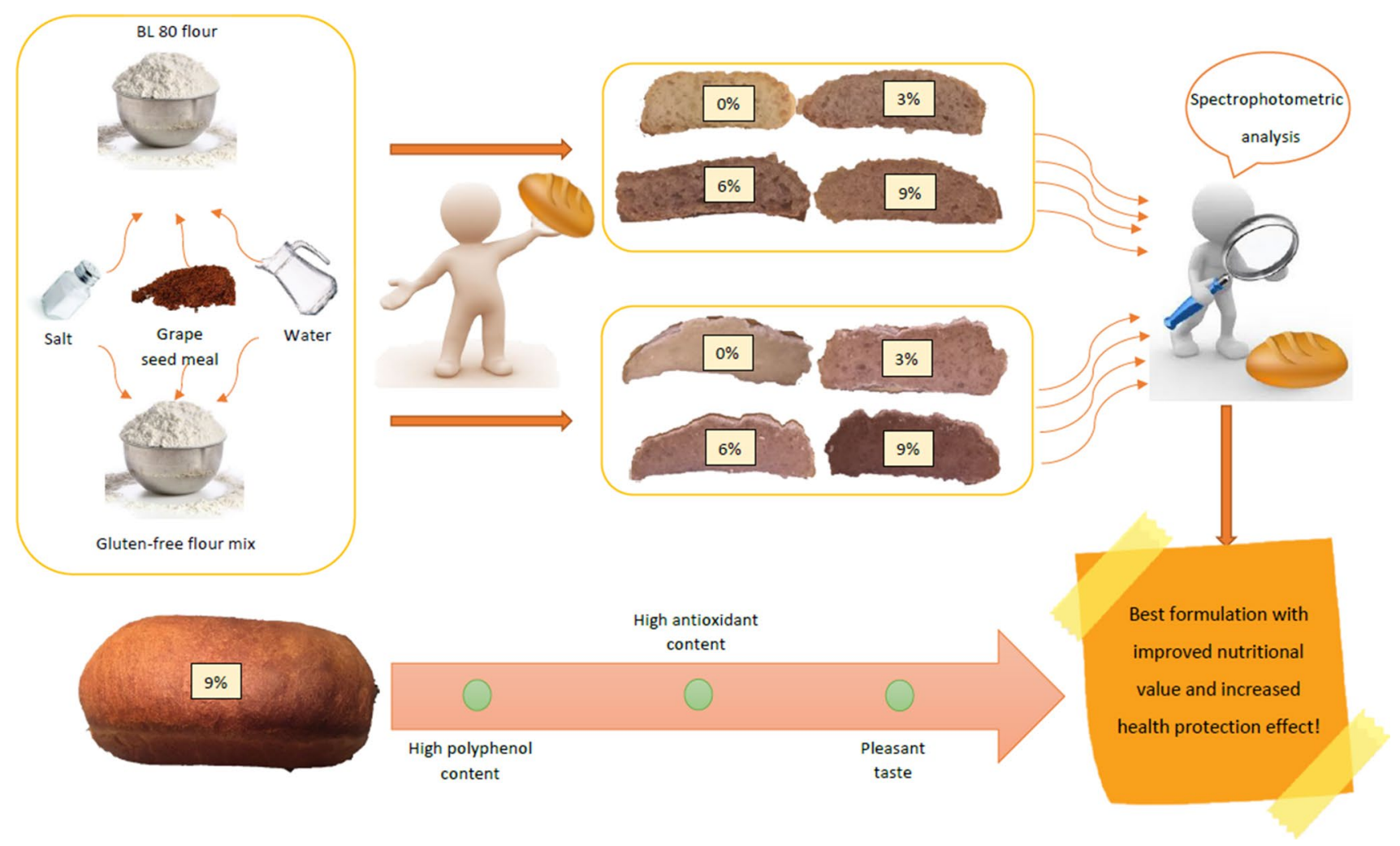

Keywords Grape seed $\cdot$ Polyphenols $\cdot$ Antioxidants $\cdot$ Functional food $\cdot$ Spectrophotometry

\section{Introduction}

Many agricultural by-products contain plant parts that are rich in phytochemicals. A good example of this is the many by-products of grape processing, such as pomace, stalk, sediment (fermentation by-product), and grape seeds. Grape marc is the main by-product of the winemaking process, which contains $38-52 \%$ grape seeds on a dry matter basis (Ghafoor et al. 2009; Maier et al. 2009). Grape by-products can serve as an excellent source of antioxidants and polyphenols for the human organism (Lorenzo et al. 2014), and these compounds have an important role in the body's immune system against viruses (Galanakis 2020; Galanakis et al. 2020). Several studies report the antiviral effect of different polyphenols during in vitro experiments (Parker et al. 2016; Yang et al. 2016). Grape seeds account for only $5 \%$ of the weight of the fruit; however, $60-70 \%$ of the total polyphenol content is concentrated in the seeds (Ribéreau-Gayon et al. 2006). The main phenolic compounds found in by-products of grape processing are $(+)$-catechin, $(-)$ - epicatechin, quercetin, myricetin, rutin, kaempferol, gallic acid, ellagic acid, siric acid, caffeic acid, and trans-resveratrol (Rubilar et al. 2013; Mattos et al. 2017). In addition to these compounds, grape marc also contains pigments such as anthocyanidins derived from malvidin, peonidine, and cyanidine (Barba et al. 2016). Polymeric tannins and monomeric flavonoids such as catechin and epicatechin in grape seed are significant because of their outstanding antioxidant activity (Peng et al. 2001). Monomeric phenolic compounds such as (+)—catechin, (-)—epicatechin, and (-)—epicatechin-3-O-gallate, and dimeric, trimeric, and tetrameric procyanidins are the most important compounds in grape seed (Mandic et al. 2008). Vázquez-Calvo et al. (2017) investigated the antiviral properties of the natural polyphenols (delphinidin and epigallocatechin gallate) against the flaviviruses (West Nile virus, Zika virus, and Dengue virus. They described that the tested polyphenols reduced the risk of infection because they affected the entry of the tested viruses into the host cell.

Functional foods are ingredients that offer health benefits that extend beyond their nutritional value. Some types contain supplements or other additional ingredients designed to improve health (Galanakis 2021). Natural antioxidants and polyphenols have a beneficial effect on human health 
because they may prevent cardiovascular disease, diabetes, and cancer (Gengaihi et al. 2014) and, due to their color, can be used in the manufacture of food supplements and food colors (Nowshehri et al. 2015; Kowalska et al. 2017). Grape antioxidants, such as phenolic acids, flavonoids, and polyphenolic compounds, can provide protection against the development of cancers (Hwang et al. 2014). Giacoppo et al. (2015) reported the neuroprotective effects of white grape polyphenols in a mouse model of experimental autoimmune encephalomyelitis. Natural polyphenols are effective inhibitors of COVID-19 main protease (Mpro), so these components may are potential therapeutic drugs (Adem et al. 2020; Galanakis 2020). The beneficial effects of grape products are also exploited in the food industry, mainly due to their antioxidant effect, which delays the oxidation of lipids, furthermore, due to their antimicrobial effect (Filocamo et al. 2015), with which they can inhibit the activities of aerobic mesophilic bacteria and lactic acid bacteria (Shahidi and Wanasundara 1992; Rababah et al. 2004; Garcia-Lomillo et al. 2014).

Due to the many health benefits of grape seeds, we investigated whether there are significant differences in the antioxidant and polyphenol contents of different grape varieties. In addition, we aimed to create a bakery product with a proven increased antioxidant and polyphenol content, which can have a beneficial effect on human health and reduce the amount of by-products from grape processing.

\section{Matherials and methods}

\section{Chemicals}

Petroleum ether (Carlo Erba, Spain) boiling at $40-70{ }^{\circ} \mathrm{C}$ was used for Soxhlet extraction. Chemicals for the determination of polyphenol and antioxidant content were 97\% ethanol (Reanal, Hungary), 99\% methanol (Reanal, Hungary), anhydrous sodium carbonate (Riedel-de Haen, Germany), Folin-Ciocalteu reagent (Merck, Germany), 2-4-6-tripyridyl-s-triazine (TPTZ) (Sigma-Aldrich, USA), acetic acid (Reanal, Hungary), anhydrous iron chloride (Merck, Germany), 98\% Trolox (Sigma-Aldrich, USA), gallic acid (Sigma-Aldrich, USA).

\section{Grape seed samples}

The dried grape seed samples were obtained from the Benedictine Pannonhalma Archabbey (Hungary). The studied varieties were the following: 'Italian Riesling,' 'Cabernet Franc,' 'Pinot Noir,' 'Sauvignon Blanc,' 'Királyleányka,' 'Rhine Riesling,' 'Merlot,' and 'Lemberger.' Grape seed meal was also examined in fatty and defatted form.

\section{Grape seed degreasing process}

\section{Sample preparation}

For the examinations, the grape seeds arrived in dried form from the Abbey. The dried grape seeds were chopped using a coffee grinder (Sencor, SCG 2050RD). Subsequently, the samples were degreased using a Soxhlet extractor.

\section{Soxhlet extraction}

The 250 -mL round-bottom flasks were heated to $90{ }^{\circ} \mathrm{C}$ and weighed on an analytical balance (Sartorius, TE214S) after cooling to room temperature. Ten grams of grape seed meal was weighed into a Whatman ${ }^{\circledR}$ cellulose extraction sheath on an analytical balance and extracted with $170 \mathrm{~mL}$ (boiling point $40-70{ }^{\circ} \mathrm{C}$ ) of petroleum ether for $3 \mathrm{~h}$. From the defatted grape seed grinds, the remaining solvent was evaporated in an oven at $40{ }^{\circ} \mathrm{C}$ for $2 \mathrm{~h}$.

\section{Fatty, and defatted grape seed sample preparation}

To determine the amount of antioxidant and polyphenol of grape seeds, the active compounds had to be extracted from the matrix by solvent extraction. For extraction, $5 \mathrm{~g}$ of each grape seed meals was weighed into an Erlenmeyer flasks on analytical balance, and $50 \mathrm{~mL}$ of an extraction mixture containing ethanol and water (50:50 v/v\%) (Vayupharp and Laksanalamai 2012) was added. The extraction was performed at $65{ }^{\circ} \mathrm{C}$ in an ultrasonic bath for $1 \mathrm{~h}$. The extracts were centrifugated at room tempeature, $2500 \mathrm{~g}, 20 \mathrm{~min}$, and the filtrate was further analyzed.

\section{Loaf making process}

Loafs were made from both gluten-free flour mixture and bread flour. In each case, $100 \mathrm{~g}$ of flour mixture contains 3,6 , and $9 \%$ grape seed flour. In order to prove the added value of the loaves, we also made control loaves from $100 \mathrm{~g}$ of gluten-free and bread flour. To each loaf were added $2 \mathrm{~g}$ of salt, $5 \mathrm{~g}$ of baking yeast, and $80 \mathrm{~mL}$ of water in the case of bread flour, and $100 \mathrm{~mL}$ of water in the case of a glutenfree flour mixture. Knead the dough from the ingredients and leave in a baking tin until it doubled in volume. Before baking, the surface of the dough was smeared with water and baked in a preheated oven at $200{ }^{\circ} \mathrm{C}$ for $45 \mathrm{~min}$.

\section{Loaf sample preparation}

The loaves were frozen and then ground with a hammer grinder. For extraction, $2 \mathrm{~g}$ of each loaf grinds was weighed into Erlenmeyer flasks on an analytical balance, and $20 \mathrm{~mL}$ of an extraction mixture containing methanol 
and water (80:20 v/v\%) was added. The extraction was performed at $65{ }^{\circ} \mathrm{C}$ in an ultrasonic bath for $1 \mathrm{~h}$. The extracts were centrifugated at room temperature, $2500 \mathrm{~g}$, $20 \mathrm{~min}$, and the filtrate was further analyzed.

\section{Determination of total antioxidant and polyphenol content}

\section{FRAP assay}

The FRAP assay procedure is based on the method described by Benzie and Strain (1996). $200 \mu \mathrm{L}$ of extracted sample, $3 \mathrm{~mL}$ of FRAP solution, and $100 \mu \mathrm{L}$ of water were pipetted into a test tube. The finished solutions were placed in a dark place for $5 \mathrm{~min}$, and then their absorbance was measured with a Spectroquant Pharo 100 spectrophotometer (Merck, Germany) at a wavelength of $593 \mathrm{~nm}$ against the blank. Trolox $(50-300 \mu \mathrm{mol} / \mathrm{mL})$ and ascorbic acid (40-500 $\mathrm{mg} / \mathrm{L})$ were used as a standard, and the results were expressed as $\mu$ mol Trolox equivalent antioxidant (TE)/g dry matter and ascorbic acid equivalent capacity (AAE)/g dry matter.

\section{Folin-Ciocalteu assay}

Determination of total polyphenol content based on the Folin-Ciocalteau method was described by Singleton et al. (1999) with some modifications (Barba et al. 2013). To $200 \mu \mathrm{L}$ of grape seed and loaf extract, $1.5 \mathrm{~mL}$ of highpurity water was pipetted, and the reagents were added: first $2.5 \mathrm{~mL}$ of Folin-Ciocalteu reagent and then $2 \mathrm{~mL}$ of $\mathrm{Na}_{2} \mathrm{CO}_{3}$. The tubes containing the mixture were placed in a dark place for $90 \mathrm{~min}$, and then the absorbance was measured at $725 \mathrm{~nm}$ versus the blank. Gallic acid was used as a standard $(25-1000 \mathrm{mg} / \mathrm{L})$.

\section{Data analysis}

The total antioxidant and polyphenol contents of grape seeds and loafs were determined in Microsoft Office Excel from the absorbance values measured for grape seeds, and loafs using the equation of the second-order least-squares analytical curve fitted to the measurement solutions using the nonlinear least-squares method. Analyses of variance (ANOVA) were used to compare the significant difference for the data $(p \leq 0.05)$. All the results are expressed as means $(n=3) \pm$ standard deviation.

\section{Results and discussion}

\section{Antioxidant content of fatty and defatted grape seeds}

The antioxidant content of fatty and Soxhlet-defatted grape seeds was determined. Furthermore, the effect of the solvent degreasing method on the antioxidant content of the samples was investigated. Results are also expressed per unit of Trolox and ascorbic acid.

The results of the antioxidant contents obtained by the FRAP assay for the examined grape varieties are shown in Table 1. Based on the results, the examined grape seed varieties showed significant differences in terms of antioxidant content. In the case of fatty and defatted samples, the same sequence can be observed between the results given in Trolox and ascorbic acid equivalent. 'Rhine Riesling' had the highest amount of antioxidants, followed by 'Lemberger,' and'Királyleányka' also for fatty and defatted samples based on the concentrations given in Trolox and ascorbic acid units. For the first three oily samples in the ranking, the concentration values were as follows :'Rhine Riesling' $(181.86 \mu \mathrm{mol}$ TE/g; 438.33 mg AAE/g), 'Lemberger' (180.05 $\mu \mathrm{mol} \mathrm{TE/g;}$ $433.97 \mathrm{mg} \mathrm{AAE} / \mathrm{g})$, and'Királyleányka' (173.46 $\mu \mathrm{mol} \mathrm{TE} / \mathrm{g}$;

Table 1 Antioxidant content of fatty and defatted seeds of different grape varieties and percentage reduction in antioxidant; different letters (a, $b$, $\mathrm{c}, \mathrm{d}, \mathrm{e}, \mathrm{f}$, and $\mathrm{g})$ denote significant differences $(p \leq 0.05)$

\begin{tabular}{|c|c|c|c|c|c|c|}
\hline \multirow[t]{2}{*}{ Grape varieties } & \multicolumn{2}{|c|}{ Fatty grape seed samples } & \multicolumn{2}{|c|}{ Defatted grape seed samples } & \multirow[t]{2}{*}{ Decrease (\%) TE } & \multirow{2}{*}{$\begin{array}{l}\text { Decrease } \\
\text { (\%) AAE }\end{array}$} \\
\hline & $(\mathrm{mg} \mathrm{TE} / \mathrm{g})$ & (mg AAE/g) & $(\mathrm{mg}$ TE/g) & (mg AAE/g) & & \\
\hline Italian Riesling & $147.96 \pm 9.52^{\mathrm{a}}$ & $356.62 \pm 22.95^{\mathrm{a}}$ & $123.71 \pm 9.10^{\mathrm{a}}$ & $298.16 \pm 21.94^{\mathrm{a}}$ & 16,38 & 16,39 \\
\hline Cabernet Franc & $100.16 \pm 7.11^{\mathrm{b}}$ & $241.41 \pm 17.13^{\mathrm{b}}$ & $41.24 \pm 3.13^{b}$ & $99.40 \pm 7.55^{\mathrm{b}}$ & 58,82 & 58,82 \\
\hline Pinot Noir & $139.08 \pm 12.38^{\mathrm{a}}$ & $335.21 \pm 29.83^{\mathrm{a}}$ & $110.04 \pm 2.49^{c}$ & $265.21 \pm 5.99^{c}$ & 20,88 & 20.88 \\
\hline Sauvignon Blanc & $153.95 \pm 4,25^{\mathrm{a}}$ & $371.07 \pm 10.24^{\mathrm{a}}$ & $71.77 \pm 0.76^{\mathrm{d}}$ & $172.99 \pm 1.84^{\mathrm{d}}$ & 53,38 & 53.39 \\
\hline Királyleányka & $173.46 \pm 1.95^{\mathrm{c}}$ & $418.08 \pm 4.70^{c}$ & $159.61 \pm 6.19^{\mathrm{e}}$ & $384.70 \pm 14.91^{\mathrm{e}}$ & 7,98 & 7.98 \\
\hline Rhine Riesling & $181.86 \pm 0.41^{\mathrm{d}}$ & $438.33 \pm 0.99^{c}$ & $176.29 \pm 0.54^{\mathrm{f}}$ & $424.91 \pm 1.30^{\mathrm{f}}$ & 3,06 & 3.06 \\
\hline Merlot & $94.80 \pm 10.63^{\mathrm{b}}$ & $228.50 \pm 25.63^{\mathrm{b}}$ & $85.55 \pm 2.60^{\mathrm{g}}$ & $206.20 \pm 6.26^{\mathrm{g}}$ & 9,76 & 9.76 \\
\hline Lemberger & $180.05 \pm 0.31^{\mathrm{d}}$ & $433.97 \pm 0.75^{\mathrm{c}}$ & $173.37 \pm 3.03^{\mathrm{f}}$ & $417.86 \pm 4.90^{\mathrm{f}}$ & 3,71 & 3.71 \\
\hline
\end{tabular}


$418.08 \mathrm{mg} \mathrm{AAE} / \mathrm{g}$ ). The order of the first three samples was the same for the defatted samples with values of 'Rhine Riesling' (176.29 $\mu \mathrm{mol} \mathrm{TE} / \mathrm{g}$; $424.91 \mathrm{mg}$ AAE/g), 'Lemberger' (173.37 $\mu \mathrm{mol}$ TE/g; 417.86 mg AAE/g), and'Királyleányka' $(159.61 \mu \mathrm{mol} \mathrm{TE} / \mathrm{g} ; 384.70 \mathrm{mg}$ AAE/g). However, it can be observed that the antioxidant content of each variety was affected to a different extent by solvent extraction (Table 1). For the different grape varieties, the results obtained with the Trolox and ascorbic acid calibration results showed the same percentage antioxidant reduction. The largest (58.82\%) decrease in antioxidants was observed for 'Cabernet Franc' and the smallest (3.06\%) for 'Rhine Riesling.'

\section{Polyfenol content of fatty, and defatted grape seeds}

The total polyphenol contents of the grape seeds are shown in Table 2. Large differences in the total polyphenol content of each grape seed variety were observed. Garcia-Jares et al. (2015) studied different Galician white grape varieties; Weider et al. (2012) examined the seeds of three different species of wild grapes; in both experiments, it was established that the vine variety affected the antioxidant and polyphenol content. The total polyphenol values of the fatty grape seeds ranged from 91.16 to $221.81 \mathrm{mg} \mathrm{GAE} / \mathrm{g}$. The highest polyphenol content in the fatty samples was measured for the 'Rhine Riesling' (221.81 mg GAE/g),

Table 2 Plyphenol content of fatty and defatted seeds of different grape varieties; different letters $(\mathrm{a}, \mathrm{b}, \mathrm{c}, \mathrm{d}, \mathrm{e}, \mathrm{f}$, and $\mathrm{g}$ ) denote significant differences $(p \leq 0.05)$

\begin{tabular}{llcr}
\hline Grape varieties & $\begin{array}{l}\text { Fatty grape seed } \\
\text { samples } \\
\text { mg GAE/g }\end{array}$ & $\begin{array}{l}\text { Defatted grape } \\
\text { seed samples }\end{array}$ & $\begin{array}{l}\text { Decrease } \\
\text { mg GAE/g }\end{array}$ \\
\hline Italian Riesling & $151.59 \pm 3.05^{\mathrm{a}}$ & $138.26 \pm 2.88^{\mathrm{a}}$ & 8.79 \\
Cabernet Franc & $113.33 \pm 3.69^{\mathrm{b}}$ & $46.01 \pm 1.80^{\mathrm{b}}$ & 59.40 \\
Pinot Noir & $152.17 \pm 11.09^{\mathrm{a}}$ & $115.22 \pm 3.14^{\mathrm{c}}$ & 24.28 \\
Sauvignon Blanc & $166.52 \pm 4.36^{\mathrm{c}}$ & $71.67 \pm 3.71^{\mathrm{d}}$ & 56.96 \\
Királyleányka & $217.39 \pm 22.41^{\mathrm{d}}$ & $162.39 \pm 11.07^{\mathrm{e}}$ & 25.30 \\
Rhine Riesling & $221.81 \pm 8.51^{\mathrm{d}}$ & $207.68 \pm 10.85^{\mathrm{f}}$ & 6.43 \\
Merlot & $91.16 \pm 6.24^{\mathrm{e}}$ & $79.57 \pm 4.65^{\mathrm{g}}$ & 12.71 \\
Lemberger & $208.70 \pm 10.04^{\mathrm{d}}$ & $207.54 \pm 10.06^{\mathrm{f}}$ & 0.48 \\
\hline
\end{tabular}

followed by 'Királyleányka' (217.39 mg GAE/g), 'Lemberger' (208.70 mg GAE/g), 'Sauvignon Blanc' (166.52 mg GAE/g), 'Pinot Noir' (152.17 mg GAE/g), 'Italian Riesling' (151.59 mg GAE/g), 'Cabernet Franc' (113.33 mg GAE/g), and 'Merlot' (91.16 mg GAE/g).

Phenolic compounds are poorly soluble in the oily phases (Benito et al. 2013), but variable amounts are transferred to the oil from the solid matrix (Kapcsándi et al. 2021) or damaged during extraction. During the solvent extraction, a decrease in polyphenol content of $0.48-59.40 \%$ was observed for the different varieties. The total polyphenol concentrations of the defatted grape seed samples were between 46.01 and 207.68 GAE/g.

\section{Antioxidant and polyphenol content of wheat, and gluten-free loafs}

The total polyphenol and antioxidant contents of bread flour and gluten-free loaves are shown in Table 3. Based on the results of the control loaves, it can be seen that the polyphenol and antioxidant content of the gluten-free flour mixture used for baking was also significantly higher than that of bread flour. The polyphenol, and antioxidant content of each of the experimental loaves was successfully increased by the addition of 3,6, and $9 \%$ grape seed meal. As the amount of grape seed meal increased, the polyphenol and antioxidant values of the loaves also increased significantly. For loaves made from bread flour, the polyphenol content was increased from $0.91 \mathrm{mg} \mathrm{GAE} / \mathrm{g}$ to $3.16 \mathrm{mg} \mathrm{GAE} / \mathrm{g}$ and their antioxidant content from $0.70 \mathrm{mg}$ AAE/g to $6.44 \mathrm{AAE} / \mathrm{g}$ by adding $9 \%$ grape seed meal. This represents an increase of $247.25 \%$ in terms of polyphenol content and $820 \%$ in terms of antioxidant content. The polyphenol content of glutenfree loaves increased by $325.9 \%$ from $1.39 \mathrm{mg} \mathrm{GAE} / \mathrm{g}$ to a final value of $5.92 \mathrm{mg} \mathrm{GAE} / \mathrm{g}$ as a result of the addition of $9 \%$ grape seed meal. A significant increase of $294.12 \%$ in the antioxidant content of gluten-free loaves was also achieved with the addition of $9 \%$ grape seed meal. Results have shown that the addition of a $9 \%$ grape seed meal does not yet cause a significant change in the taste of the loaves, but if added in larger quantities it already significantly reduces the enjoyment value of the final product.

Table 3 Antioxidant and polyphenol content of loaves added with different amounts of grape seed meal; different letters (a, b, c, and d) denote significant differences $(p \leq 0.05)$

\begin{tabular}{|c|c|c|c|c|c|c|c|c|}
\hline & \multicolumn{2}{|l|}{ Control } & \multicolumn{2}{|c|}{$3 \%$ grape seed } & \multicolumn{2}{|c|}{$6 \%$ grape seed } & \multicolumn{2}{|c|}{$9 \%$ grape seed } \\
\hline & TPC* & FRAP** & TPC & FRAP & ТPC & FRAP & TPC & FRAP \\
\hline Bread flour & $0.91 \pm 0.07^{\mathrm{a}}$ & $0.70 \pm 0.03^{\mathrm{a}}$ & $1.96 \pm 0.12^{\mathrm{b}}$ & $3.46 \pm 0.47^{\mathrm{b}}$ & $2.61 \pm 0.25^{\mathrm{c}}$ & $5.02 \pm 0.14^{\mathrm{c}}$ & $3.16 \pm 0.26^{\mathrm{d}}$ & $6.44 \pm 0.12^{\mathrm{d}}$ \\
\hline Gluten-free flour & $1.39 \pm 0.15^{\mathrm{a}}$ & $2.55 \pm 0.27^{\mathrm{a}}$ & $3.63 \pm 0.11^{\mathrm{b}}$ & $5.75 \pm 0.06^{\mathrm{b}}$ & $4.16 \pm 0.20^{\mathrm{c}}$ & $7.83 \pm 1.04^{\mathrm{c}}$ & $5.92 \pm 0.19^{d}$ & $9.75 \pm 1.07^{\mathrm{d}}$ \\
\hline
\end{tabular}

*mg GAE/g

**mg AAE/g 
Numerous studies show that cereal-based foods can be enriched by addition natural antioxidants. For example, biscuits and breads were fortified by the addition of mango (Vergara-Valencie et al. 2007), and it was found that the addition of green tea can increase the antioxidant content of cakes (Lu et al. 2010). The studied grape seed varieties are suitable for the production of functional bakery products based on their polyphenol and antioxidant content and have favorable, health-protecting properties in terms of their quality. Peng et al. (2010) found that the addition of grape seed extract can increase the antioxidant activity of breads. Benes and Szedljak (2019) examined durum wheat based breads enriched with hemp seed flour and found that hemp flour has improved the antioxidant and polyphenol content of bread. It has been shown that grape variety influences the polyphenol and antioxidant content of grape seeds; however, no clear difference can be detected between red and white grape varieties. Meral and Doğan (2013) studied brads enriched with grape seed flour. They successfully increased the antioxidant and polyphenol content of breads, but detected in smaller amounts. This was presumably due to the improperly chosen extractant pure methanol, which does not provide the best extraction efficiency of these compounds. It has been found that solvent extraction has a different effect on the seeds of each grape variety. Bakery products enriched with the grape meals were produced, and their increased antioxidant and polyphenol content was confirmed by spectrophotometric analysis.

Acknowledgements This research was supported by the ÚNKP-20-4-II New National Excellence Program of the Ministry for Innovation and Technology from the source of the National Research, Development and Innovation Fund.

Funding Open access funding provided by Széchenyi István University (SZE).

\section{Declarations}

Conflict of interest The authors have declared no conflict of interest.

Open Access This article is licensed under a Creative Commons Attribution 4.0 International License, which permits use, sharing, adaptation, distribution and reproduction in any medium or format, as long as you give appropriate credit to the original author(s) and the source, provide a link to the Creative Commons licence, and indicate if changes were made. The images or other third party material in this article are included in the article's Creative Commons licence, unless indicated otherwise in a credit line to the material. If material is not included in the article's Creative Commons licence and your intended use is not permitted by statutory regulation or exceeds the permitted use, you will need to obtain permission directly from the copyright holder. To view a copy of this licence, visit http://creativecommons.org/licenses/by/4.0/.

\section{References}

Adem S, Eyupoglu V, Sarfraz I, Rasul A, Ali M (2020) Identification of potent COVID-19 main protease (Mpro) inhibitors from natural polyphenols: an in silico strategy unveils a hope against CORONA. Preprints 2020030333

Barba FJ, Esteve MJ, Tedeschi P et al (2013) A comparative study of the analysis of antioxidant activities of liquidfoods employing spectrophotometric, fluorometric, and chemiluminescent methods. Food Anal Methods 6:317-327. https://doi.org/10.1007/ s12161-012-9441-3

Barba FJ, Zhu Z, Koubaa M, Sant'Ana AS, Orlien V (2016) Green alternative methods for the extraction of antioxidant bioactive compounds from winery wastes and by-products: a review. Trends Food Sci Technol 49:96-109

Benes E, Szedljak I (2019) Comparison of chemical characteristics and technological parameters in durum wheat based breads enriched with hemp seed flour. Élelmiszervizsgálati Közlemények 65(4):2716-2727

Benito M, Lasa JM, Gracia P, Oria R, Abenoza M, Varona L, SánchezGimeno AC (2013) Olive oil quality and ripening in super-highdensity Arbequina orchard. J Sci Food Agric 93(9):2207-2220

Benzie IFF, Strain JJ (1996) The ferric reducing ability of plasma (FRAP) as a measure of "antioxidant power": the FRAP assay. Anal Biochem 239(1):70-76

Filocamo A, Bisignano C, Mandalari G, Navarra M (2015) In vitro antimicrobial activity and effect on biofilm Production of a white grape juice (Vitis vinifera) extract. Evidence-Based Complement Altern Med. https://doi.org/10.1155/2015/856243

Galanakis CM (2020) The Food Systems in the Era of the Coronavirus (COVID-19) Pandemic Crisis. Foods 9(4):523

Galanakis CM (2021) Functionality of food components and emerging technologies. Foods 10:128

Galanakis CM, Aldawoud TMS, Rizou M, Rowan NJ, Ibrahim SA (2020) Food ingredients and active compounds against the Coronavirus disease (COVID-19) pandemic: a comprehensive review. Foods 9(11):1701

Garcia-Jares C, Vazquez A, Lamas JP, Pajaro M, Alvarez-Casas M, Lores M (2015) Antioxidant white grape seed phenolics: pressurized liquid extracts from different varieties. Antioxidants (basel) 4(4):737-749

García-Lomillo J, González-San José ML, Del Pino-García R, Rivero-Pérez MD, Muñiz-Rodríguez P (2014) Antioxidant and antimicrobial properties of wine byproducts and their potential uses in the food industry. J Agric Food Chem 62:12595-12602

Gengaihi SEI, Ella FMA, Emad MH, Shalaby E, Doha H (2014) Antioxidant activity of phenolic compounds from different grape wastes. J Food Process Technol 5:296-300

Ghafoor K, Choi YH, Jeon JY, Jo IH (2009) Optimization of ultrasound-Assisted extraction of phenolic compounds, antioxidants, and anthocyanins from grape (Vitis vinifera) seeds. J Agric Food Chem 57:4988-4994

Giacoppo S, Galuppo M, Lombardo GE, Ulaszewska MM, Mattivi F, Bramanti P, Mazzon E, Navarra M (2015) Neuroprotective effects of a polyphenolic white grape juice extract in a mouse model of experimental autoimmune encephalomyelitis. Fitoterapia 103:171-186

Hwang SJ, Yoon WB, Lee OH, Cha SJ, Kim JD (2014) Radicalscavenging-linked antioxidant activities of extracts from black chokeberry and blueberry cultivated in Korea. Food Chem 146:71-77

Kapcsándi V, HancznéLakatos E, Sik B, Linka LÁ, Székelyhidi R (2021) Characterization of fatty acid, antioxidant, and polyphenol content of grape seed oil from different Vitis vinifera L. varieties. OCL 28:30 
Kowalska H, Czajkowska K, Cichowska J, Lenart A (2017) What's new in biopotential of fruit and vegetable by-products applied in the food processing industry. Trends Food Sci Technol 67(Supplement C):150-159

Lorenzo JM, Sineiro J, Amado IR, Franco D (2014) Influence of natural extracts on the shelf life of modified atmosphere-packaged pork patties. Meat Sci 96:526-534

Lu TM, Li CC, Mau JL, Lin SD (2010) Quality and antioxidant property of green tea sponge cake. Food Chem 119:1090-1095

Maier T, Schieber A, Kammerer DR, Carle R (2009) Residues of grape (Vitis vinifera $\mathrm{L}$.) seed oil production as a valuable source of phenolic antioxidants. Food Chem 112:551-559

Mandic AI, Đilas SM, Ćetković GS, Čanadanović-Brunet JM, Tumbas VT (2008) Polyphenolic Composition and Antioxidant Activities of Grape Seed Extract. Int J Food Prop 11:713-726

Mattos GN, Tonon RV, Furtado AAL, Cabral LMC (2017) Grape byproduct extracts against microbial proliferation and lipid oxidation: a review. J Sci Food Agric 97:1055-1064

Meral R, Doğan ÍS (2013) Grape seed as a functional food ingredient in bread-making. Int J Food Sci Nutr 64(3):372-379

Nowshehri JA, Bhat ZA, Shah MY (2015) Blessings in disguise: biofunctional benefits of grape seed extracts. Food Res Int 77(Part 3):333-48

Parker S, May B, Zhang C, Zhang AL, Lu C, Xue CCA (2016) Pharmacological review of bioactive constituents of Paeonia lactiflora Pallas and Paeonia veitchii Lynch. Phytother Res 30:1445-1473

Peng Z, Hayasaka Y, Iland PG, Sefton M, HØj P, Waters EJ (2001) Quantitative analysis of polymeric procyanidins (tannins) from grape (Vitis Vinifera) seeds by reverse phase highperformance liquid chromatography. J Agric Food Chem 49:26-31

Peng X, Ma J, Cheng KW, Jiang Y, Chen F, Wang M (2010) The effects of grape seed extract fortification on the antioxidant activity and quality attributes of bread. Food Chem 119:49-53

Rababah TM, Hettiarachchy NS, Horax R (2004) Total Phenolics and Antioxidant Activities of Fenugreek, Green Tea, Black Tea, Grape Seed, Ginger, Rosemary, Gotu Kola, and Ginkgo Extracts, Vitamin E, and tert-Butylhydroquinone. J Agric Food Chem $52: 5183-5186$
Ribéreau-Gayon P, Glories Y, Maujean A, Dubordieu D (2006) Handbook of Enology. John Wiley \& Sons Ltd., Chichester, UK

Rubilar JF, Cruz RMS, Silva HD, Vicente AA, Khmelinskii I, Vieira MC (2013) Physico-mechanical properties of chitosan films with carvacrol and grape seed extract. J Food Eng 115:466-474

Shahidi F, Wanasundara PK (1992) Phenolic antioxidants. Crit Rev Food Sci Nutr 32:67-103

Singleton VL, Orthofer R, Lamuela-Raventos RM (1999) Analysis of total phenols and otheroxidation substrates and antioxidants by means of Folin-Ciocalteu reagent. Methods Enzymol 299:152-178

Vayupharp B, Laksanalamai V (2012) Recovery of antioxidants from grape seeds and its application in fried food. J Food Process Technol 3:4

Vázquez-Calvo Á, De Oya NJ, Martín-Acebes MA, Garcia-Moruno E, Saiz J-C (2017) Antiviral properties of the natural polyphenols delphinidin and epigallocatechin gallate against the flaviviruses West Nile virus, Zika virus, and dengue virus. Front Microbiol $8: 1314$

Vergara-Valencia N, Granados-Perez E, Agama-Acevedo E, Tovar J, Ruales J, Bello-Perez LA (2007) Fibre concentrate from mango fruit: characterization, associated antioxidant capacity and application as a bakery product ingredient. LWT 40:722-729

Weidner S, Powałka A, Karamać M, Amarowicz R (2012) Extracts of phenolic compounds from seeds of three wild grapevines: comparison of their antioxidant activities and the content of phenolic compounds. Int J Mol Sci 13:3444-3457

Yang C, Zhi X, Xu H, Lv M (2016) Advances on semisynthesis, total synthesis, and structure-activity relationships of honokiol and magnolol derivatives. Mini-Rev Med Chem 16:1

Publisher's Note Springer Nature remains neutral with regard to jurisdictional claims in published maps and institutional affiliations. 